\title{
Pathological Narcissism and Acute Anxiety Symptoms After Trauma: A Study of Israeli Civilians Exposed to War
}

\author{
Avi Besser, Virgil Zeigler-Hill, Aaron L. Pincus, and Yuval Neria
}

\begin{abstract}
Objective: Diathesis-stress models of posttraumatic stress disorder (PTSD) hypothesize that exposure to trauma may interact with individual differences in the development of PTSD. Previous studies have not assessed immediate responses to a proximate stressor, but the current "natural laboratory" study was designed to empirically test the role that individual differences in pathological narcissism may play in the development of acute anxiety symptoms among civilians facing rocket and missile fire. Method: We assessed demographic features, trauma exposure severity, narcissistic personality features, and acute anxiety symptoms (PTSD and General Anxiety Disorder [GAD]) among 342 Israeli female adults during the November 2012 eruption of violence in the Middle East. Results: Results demonstrate an association between exposure severity and acute anxiety symptoms (both PTSD and GAD) for individuals with high levels of pathological narcissism but not for those with low levels of pathological narcissism. These results suggest that individuals with narcissistic personality features are at high risk for the development of acute anxiety symptoms following exposure to uncontrollable and life-threatening mass trauma. Conclusion: The findings underscore the role of intra-personal resources in the immediate psychological aftermath of war by highlighting the increased risk associated with narcissistic personality features. Theoretical and clinical implications of the findings are discussed.
\end{abstract}

Avi Besser, $P h D$, is affilliated with the Department of Behavioral Sciences and Center for Research in Personality, Life Transitions, and Stressful Life Events at Sapir Academic College in Sderot, Israel. Virgil Zeigler-Hill, PhD, is with the Department of Psychology at Oakland University in Rochester, Michigan. Aaron L. Pincus, PhD, is with the Department of Psychology at Pennsylvania State University in University Park, Pennsylvania. Yuval Neria, PhD, is affiliated with the New York State Psychiatric Institute as well as the departments of Psychiatry and Epidemiology at Columbia University Medical Center in New York City.

Grateful thanks are extended to all of the participants in this study as well as to the anonymous reviewers for their constructive suggestions and comments on an earlier draft of this paper.

Address correspondence to Avi Besser, Center for Research in Personality, Life Transitions, and Stressful Life Events, Sapir Academic College, D. N. Hof Ashkelon 79165, Israel. E-mail: besser@mail.sapir.ac.il or to Virgil Zeigler-Hill, Department of Psychology, Oakland University, 111 Pryale Hall, Rochester, MI 48309. E-mail: zeiglerh@oakland. edu. 
Exposure to war requires civilians to mobilize internal and external resources to effectively cope with the trauma, which may place them at considerable risk for a range of mental health problems. The present study aimed to examine the "diathesisstress" model suggesting that exposure to traumatic events interacts with individual differences to produce trauma-related outcomes. The diathesis that is of interest to us involves the association between personality and the development of emotional problems among civilians exposed to war because this topic is of both theoretical and clinical interest. More specifically, we focused on the potential role that pathological narcissism may play in exacerbating the risk for developing acute anxiety symptoms-posttraumatic stress disorder (PTSD) and generalized anxiety disorder (GAD)-during the exposure to uncontrollable, highly aversive, and lifethreatening traumatic events.

Although a number of studies have pointed to an elevated risk of acute anxiety symptoms in the aftermath of trauma (Ghafoori et al., 2009; Jordan et al., 2004; Liverant, Hoffman, \& Litz, 2004), only a few have assessed these symptoms during the actual exposure to trauma (e.g., Neria, Besser, Kipper, \& Westphal, 2010). Over the past 12 years, large civilian populations in southwestern Israel and the Gaza Strip have been exposed to recurrent bouts of missile fire across the Gaza-Israel border. A number of prior studies have examined the mental health consequences of ongoing exposure on the Israeli side, suggesting a broad impact (e.g., Besser \& Neria, 2009, 2010, 2012; Besser, Neria, \& Haynes, 2009; Besser \& Priel, 2010a; Neria et al., 2010). Recently, Israeli and Palestinian civilians on both sides of the Gaza-Israel border have witnessed yet another round of escalation in the ongoing conflict when long-distance missiles were launched by Hamas and Islamic Jihad forces from the Gaza Strip that were-for the first time-capable of reaching cities in central Israel that were as far as $80 \mathrm{~km}$ from the bor- der. As of November 2012, approximately 2,256 rockets had been launched at Israel within the past year, with more than 1,500 during data collection for this study (November 14, 2012 to November 21, 2012).

Previous reviews have documented the negative impact of exposure to mass trauma among civilians (see Neria, Nandi, \& Galea, 2008; Norris et al., 2002). The risk of anxiety disorders-including PTSD and GADhas been repeatedly shown to be associated with the severity of exposure to potentially traumatic events. For example, low levels of PTSD symptoms have been reported by individuals indirectly exposed to mass trauma (e.g., Ahern, Galea, Resnick, \& Vlahov, 2004; Neria et al., 2006), with higher levels of PTSD often being reported by those who were directly exposed to trauma (e.g., for a review, see Galea et al., 2002; Hobfoll et al., 2008; Shalev \& Freedman, 2005; or Weinberg, Besser, Campeas, Shvil, \& Neria, 2012). It is important to note, however, that the psychological impact of mass trauma is not limited to PTSD. Other mental health problems-such as GAD symptoms-have also been reported in the aftermath of largescale traumatic events (e.g., Ghafoori et al., 2009). In order to build on the existing research literature, we decided to assess acute anxiety symptoms that were captured by measures of both PTSD and GAD diagnostic criteria.

Previous research shows that personality traits have the capacity to shape how individuals perceive and respond to traumatic events, suggesting that personality may play a significant role in the vulnerability to acute anxiety symptoms (e.g., Besser \& Neria, 2010, 2012; Besser, Neria, \& Haynes, 2009; Besser \& Priel, 2010a; Cox, MacPherson, Enns, \& McWilliams, 2004; Neria et al., 2010). A particularly interesting personality feature that may play a role in responses to traumatic events is narcissism (e.g., Bachar, Hadar, \& Shalev, 2005). Previous research shows that individuals with narcissistic personality features are often highly reactive 
TABLE 1. Descriptive Statistics for Demographic Features Across the Three Exposure Severity Regions

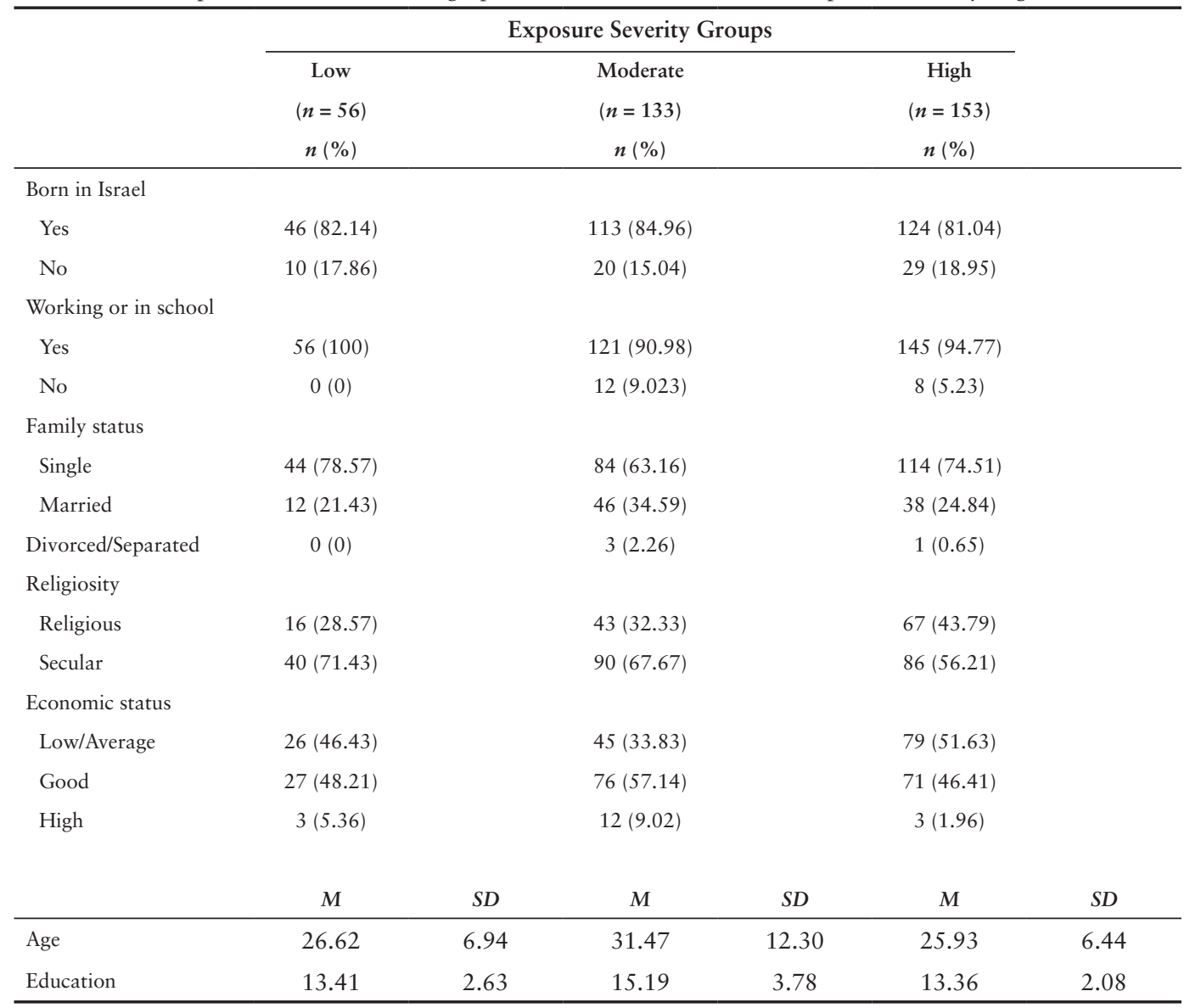

to relatively mundane negative events (e.g., achievement failures) that have the capacity to threaten their positive views of themselves (Besser \& Zeigler-Hill, 2010, 2011; Besser \& Priel, 2010b; Zeigler-Hill \& Besser, 2013; Zeigler-Hill, Myers, \& Clark, 2010), highly sensitive to feeling controlled and antagonized by others (Hopwood et al., 2011), and more likely to perceive themselves to be victims of interpersonal transgressions in daily life (McCullough, Emmons, Kilpatrick, \& Mooney, 2003). The reason for the heightened reactivity and sensitivity of individuals with narcissistic personality features is that their self-concepts are grandiose yet extremely vulnerable to threat (Kealy \& Rasmussen, 2012; Morf \& Rhodewalt, 2001; Pincus \&
Roche, 2011; Zeigler-Hill \& Jordan, 2011). It has often been suggested that the heightened reactivity of individuals with high levels of narcissism may extend to traumatic events (e.g., Abraham, 1921; Kelman, 1946; Simon, 2002; Ulman \& Brothers, 1987). The susceptibility of individuals with narcissistic personality features to extreme responses in the aftermath of traumatic events is thought to be due to their experience of the traumatic event as a sort of narcissistic injury that disturbs their grandiose self-views. In essence, the traumatic experience is believed to undermine their sense of omnipotent control over self, others, and the world, and challenges their view of themselves as being capable of effectively coping with any sort of nega- 
tive experience. This is consistent with the view that narcissism may develop, in part, as a defense against feelings of vulnerability (e.g., Kealy \& Rasmussen, 2012; Kernberg, 1998; Reich, 1960; Ronningstam, 2011). Unlike others who may view themselves as reasonably safe from harm, individuals with narcissistic personality features may believe they are invulnerable (e.g., Barry, Pickard, \& Ansel, 2009). This sort of mental representation of the self has been referred to as an overvalued (Foa \& Riggs, 1993) or inflexible positive (Elliott \& Lassen, 1997) schema.

Following the traumatic event, individuals with narcissistic personality features are commonly confronted with the fact that they are actually quite ordinary and as vulnerable to these events as all other individuals. This sudden and dramatic change in self-view may trigger feelings of inadequacy or self-loathing which may culminate in especially extreme emotional reactions to these traumatic events. Despite the considerable speculation concerning narcissistic personality features and reactions to traumatic events, this connection has received relatively little empirical attention. One exception is the work of Stinson and his colleagues (2008) who used 34,653 participants enrolled in an epidemiological study to examine the comorbidity of narcissistic personality disorder (NPD) with Axis I psychiatric disorders. After controlling for demographic variables and all other psychiatric disorders, they calculated a 1.7 odds ratio for meeting an NPD diagnosis given a 12 -month PTSD diagnosis and a 1.9 odds ratio for meeting an NPD diagnosis given a lifetime PTSD diagnosis. These were among the highest rates of comorbid NPD-Axis I diagnoses reported. However, the few other attempts to address this connection have been limited by such issues as extremely small sample sizes (e.g., Clemence, Perry, \& Plakun, 2009; Garfield \& Leveroni, 2000; Johnson, 1995) or the use of unvalidated assessment instruments with inadequate psychometric properties (e.g., Bachar et al., 2005).

\section{Overview and Predictions}

The goal of the present study was to extend what is currently known about the association between narcissism and responses to traumatic events (i.e., immediate responses to a proximate stressor). To accomplish this goal, we evaluated the associations between the levels of pathological narcissism possessed by participants in regions of Israel who were experiencing different levels of exposure to missile fire and their acute anxiety symptoms (PTSD and GAD symptoms). Our prediction was that pathological narcissism would moderate the association between severity of exposure to traumatic events and psychological symptoms. More specifically, we expected individuals with higher levels of pathological narcissism to be especially responsive to these negative experiences such that they would report the highest levels of acute anxiety symptoms (PTSD and GAD symptoms) when they experienced high levels of threat. The rationale for this prediction was that pathological narcissism would serve as a diathesis leading individuals to be especially reactive to uncontrollable and potentially life-threatening events because of the capacity of these events to threaten their grandiose feelings of invulnerability and omnipotent control, leading to the marked dysregulation of the self and affective processes that characterizes individuals with narcissistic personality features (Pincus \& Lukowitsky, 2010; Pincus, Roche, \& Good, in press).

\section{METHOD}

\section{Participants and Procedure}

The data for this paper are derived from a project designed to study the mental health consequences of the 2012 Israel-Gaza war. We recruited civilians facing different levels of potential threat from missile fire 
originating from the Gaza Strip during the "Pillar of Defense" Israel Defense Forces operation that lasted from November 14, 2012 to November 21, 2012. This was the first time that long-distance missiles were used to reach locations that were as far as $80 \mathrm{~km}$ from the border (e.g., Tel-Aviv, Jerusalem). The time available for residents to take shelter between the air-raid sirens warning of incoming fire and the impact of the missiles varied depending on their distance from the Gaza Strip. The amount of warning ranged from 15 seconds in the border areas (up to $7 \mathrm{~km}$ from Gaza) to 120 seconds in areas that were $75-80 \mathrm{~km}$ from the border (alarm zones were defined by the Israeli Home Front Command). The sample included 342 Jewish Israeli adult women with a mean age of 28.19 years $(S D=9.58)$ and 14.08 years $(S D=3.06)$ of formal education. The demographic features of our participants are presented in Table 1 . The sample was taken from three regions of Israel: $44.7 \%(n=153)$ lived in southeastern Israel $7-40 \mathrm{~km}$ from the border and were under severe threat of missile strikes at the time they completed the survey; $38.9 \%(n=133)$ lived in central Israel $65-75 \mathrm{~km}$ from the border and were under a moderate level of threat from missile strikes at the time they completed the survey; and $16.4 \%(n=56)$ lived in southeastern Israel $5-60 \mathrm{~km}$ from the border but were only under low levels of threat from missile strikes. It is important to note that simple geographic distance from the border was not equivalent to exposure severity in the present study. The reason for this is that some areas that were farther away from the border (e.g., Tel Aviv, Jerusalem) were targeted more often than other areas closer to the border.

Because we aimed to investigate participant reports "in vivo" under life-threatening conditions, we opted to rely on web administration of the study, which allowed us to simultaneously collect data from individuals in the three regions of Israel that were under attack. Consequently, we used a snowball sampling technique that utilized In- ternet-based social media outlets (e.g., Facebook) to invite individuals in these areas of Israel to participate in the study and requested that they consider inviting their friends and family members to take part in the study as well. Of the 476 participants ( $17 \%$ men) who provided informed consent to participate, $366(77 \%$ of the original with only $7 \%$ men) completed the study questionnaires. Data from the 24 men were excluded due to the low participation rate of men, which resulted in our final sample of 342 women. We believe that the low participation rate of men for our study may have been due, at least in part, to the fact that men were at greater risk for being called into active service during this conflict. Invitations to participate were sent on November 14, 2012, and data collection closed at the time of declaration of ceasefire on November 21, 2012. The study was approved by the Sapir College Department of Behavioral Sciences Ethics Committee, ensuring privacy and confidentiality. All respondents provided electronic informed consent before participating in the study.

\section{Measures}

Exposure Severity. Exposure severity was defined by the intensity of the missile and rocket attacks in the location where each participant completed the study. Three levels of exposure severity were utilized: (1) High Exposure Severity to missile and rocket attacks (i.e., southeastern Israel, 7-40 km from the border which was under massive attacks); (2) Moderate Exposure Severity to missile and rocket fire (i.e., central Israel, $65-75 \mathrm{~km}$ from the border that was under moderate missile fire); and (3) Low Exposure Severity to missile and rocket attacks (i.e., southeastern Israel $50-60 \mathrm{~km}$ from the border which experienced infrequent missile fire).

Pathological Narcissism. The Pathological Narcissism Inventory (PNI; Pincus, 2013; Pincus et al., 2009) was used to assess the pathological form of narcissism. The PNI 
is a 52-item measure for which responses were made on scales ranging from 0 (not at all like me) to 5 (very much like me). This instrument captures a range of phenomena associated with pathological narcissism, such as the tendency to exploit others (e.g., "I can make anyone believe anything I want them to"), experience grandiose fantasies (e.g., "I often fantasize about performing heroic deeds"), and the tendency to become dysregulated in response to narcissistic injury (e.g. "I typically get very angry when I'm unable to get what I want from others"). A large body of experimental (e.g., Fetterman \& Robinson, 2010), clinical (e.g., Ellison, Levy, Cain, Ansell, \& Pincus, 2013), longitudinal (e.g., Roche, Pincus, Conroy, Hyde, \& Ram, in press), and correlational (e.g., Thomas, Wright, Lukowitsky, Donnellan, \& Hopwood, 2012) research supports the validity of the PNI. In the present study, the PNI had a high level of internal consistency $(a=0.96)$.

Acute Anxiety Symptoms. We measured acute anxiety symptoms using a measure of PTSD symptoms as well as a measure of GAD symptoms. Symptoms of PTSD were assessed using the PTSD Checklist-Civilian Version (PCL-C; Weathers \& Ford, 1996). This 17-item self-administered questionnaire is based on the diagnostic criteria for PTSD from the Diagnostic and Statistical Manual of Mental Disorders, 4th edition (DSM-IV; American Psychiatric Association, 1994). These criteria relate to three separate PTSD symptom clusters: re-experiencing (e.g., "Suddenly acting or feeling as if a stressful experience was happening again [as if you were reliving it]?”), numbing/avoidance (e.g., "Avoiding activities or situations because they reminded you of your stressful experience?"), and hyperarousal (e.g., "Having difficulty concentrating?"). Respondents were asked to rate the symptoms of PTSD they experienced during the past month as related to the stressful experience of and response to the fighting between Israel and Hamas (i.e., rocket and missile fire) using scales that ranged from 1 (not at all) to 5 (extremely). The total score on the PCL-C was our index of PTSD symptoms, which ranged from 17 to 85, with higher scores representing higher levels of PTSD symptoms. The internal consistency coefficient for the PCL-C was 0.93 for the present study. We assessed GAD symptoms with the Generalized Anxiety Disorder Scale (GAD-7; Spitzer, Kroenke, Williams, \& Lowe, 2006), which is a seven-item instrument corresponding to the diagnostic criteria for generalized anxiety disorder. Participants were asked to respond to each item using scales that ranged from 0 (not at all) to 3 (almost every day). Scores for the GAD-7 ranged from 0 to 21, with higher scores representing higher levels of GAD symptoms. This scale has been found to have adequate psychometric properties (e.g., Spitzer et al., 2006). The internal consistency for the GAD-7 was 0.94 for the present study.

\section{Data Analytic Strategy}

Descriptive statistics were calculated separately for each of the three exposure severity groups. We first examined whether there were significant differences between the three groups in terms of demographics, narcissism, PTSD symptoms, and GAD symptoms. Then, we conducted bivariate analyses of the associations that narcissism had with PTSD and GAD symptoms for individuals living in each region. The primary purpose of our study was to determine whether the levels of pathological narcissism possessed by civilians were associated with the symptoms they reported under life-threatening conditions. This was accomplished by conducting hierarchical multiple regression analyses in which the self-reported ratings of PTSD and GAD symptoms were regressed onto exposure severity, pathological narcissism, and demographic features. We used orthogonal polynomials as the coding vectors for exposure severity (a categorical pre- 
dictor consisting of low, moderate, and high levels of exposure severity). This allowed us to more easily interpret the two-way interactions that emerged from the analyses. More specifically, two orthogonal polynomials were created to distinguish between the three levels of exposure severity that characterized the participants. The first of these orthogonal polynomials was a linear term that was coded as follows: Low Exposure Severity [-1], Moderate Exposure Severity [0], and High Exposure Severity [+1]. The second orthogonal polynomial was a quadratic term that was coded as follows: Low Exposure Severity [+1], Moderate Exposure Severity [-2], and High Exposure Severity $[+1]$. It was important for us to include the quadratic term so that we could determine whether there was a curvilinear pattern in the data relating exposure to acute anxiety symptoms. ${ }^{1}$ For these analyses, the main effect terms for exposure severity (i.e., linear and quadratic effects), age, and education levels were entered on Step 1. The main effect of pathological narcissism was entered on Step 2. The two-way interactions of exposure severity (i.e., linear and quadratic effects) with narcissism were entered on Step 3 . These regression analyses were followed by the simple slopes tests that are used to describe interactions involving continuous variables (Aiken \& West, 1991).

\section{RESULTS}

\section{Bivariate Relations Between Severity of Exposure and the Study Variables}

We first examined the bivariate relations between severity of exposure and the demographic characteristics, pathological narcissism, PTSD symptoms, and GAD symptoms. Significant differences were found between the groups in terms of age $(F(2,339)$ $=13.77, p<.001)$ and education $(F(2,339)=$ $15.55, p<.001)$, such that participants in the moderate exposure severity region of Israel (i.e., the center of Israel) were older and had more years of formal education than those in the other two exposure severity regions. No significant differences were found between the groups in terms of place of birth $\left(\chi^{2}=\right.$ $.78, p=.68)$, being currently employed or in school $\left(\chi^{2}=1.70, p=.20\right)$, family status $\left(\chi^{2}=\right.$ $7.68, p=.11)$, or religiosity $\left(\chi^{2}=.1 .14, p=\right.$ .29 ). As a consequence of these results, we controlled for the demographic features of age and educational status in our subsequent analyses.

Levels of pathological narcissism reported by participants in the three exposure severity regions did not differ $(F(2,339)=$ $0.36, n s)$. However, as expected, significant differences emerged between exposure severity, PTSD symptoms $(F(2,339)=11.84, p$ $<.001)$, and GAD symptoms $(F(2,339)=$ $10.06, p<.001)$. Post hoc tests found that participants in the high exposure severity regions reported the highest levels of PTSD symptoms and GAD symptoms ( $t$ s $>3.53$, $p s<.001)$ but that the differences between low and moderate exposure severity did not reach conventional levels of significance $(t s<$ 1.13, ps > .50).

Correlations for the entire sample revealed that pathological narcissism had significant positive associations with PTSD symptoms $(r(342)=.35, p<.001)$ and GAD symptoms $(r(342)=.28, p<.001)$. Zeroorder correlations within each of the exposure severity groups are summarized in Table 2 . The pattern of correlations revealed that pathological narcissism was positively associated with the severity of PTSD and GAD symptoms reported by participants in the moderate and high exposure severity regions

1. We also conducted similar analyses that did not include the quadratic orthogonal polynomial term. The linear effects that emerged from those analyses were very similar to those reported for the analyses that included the quadratic term. As a result, we only report the results of the analyses that included the quadratic term. 
TABLE 2. Correlations Between Pathological Narcissism, PTSD Symptoms, and GAD Symptoms for the Exposure Severity Groups

\begin{tabular}{|c|c|c|c|}
\hline & \multicolumn{3}{|c|}{ Low Exposure Severity $(n=56)$} \\
\hline & 1 & 2 & 3 \\
\hline 1. Pathological Narcissism & - & & \\
\hline 2. PTSD Symptoms & .10 & - & \\
\hline 3. GAD Symptoms & -.05 & $.73 * *$ & - \\
\hline Mean & 2.06 & 30.45 & 5.70 \\
\hline Standard Deviation & 0.80 & 13.05 & 5.24 \\
\hline \multirow[t]{3}{*}{$\alpha$} & 0.95 & 0.92 & 0.92 \\
\hline & \multicolumn{3}{|c|}{ Moderate Exposure Severity $(n=133)$} \\
\hline & 1 & 2 & 3 \\
\hline 1. Pathological Narcissism & - & & \\
\hline 2. PTSD Symptoms & $.37 * * *$ & - & \\
\hline 3. GAD Symptoms & $.35^{* * *}$ & $.82 * *$ & - \\
\hline Mean & 1.98 & 32.85 & 6.77 \\
\hline Standard Deviation & 0.79 & 13.12 & 6.13 \\
\hline \multirow[t]{3}{*}{$\alpha$} & 0.95 & 0.92 & 0.94 \\
\hline & \multicolumn{3}{|c|}{ High Exposure Severity ( $n=153$ ) } \\
\hline & 1 & 2 & 3 \\
\hline 1. Pathological Narcissism & - & & \\
\hline 2. PTSD Symptoms & $.42 * *$ & - & \\
\hline 3. GAD Symptoms & $.31^{* * *}$ & $.77^{* * *}$ & - \\
\hline Mean & 2.12 & 39.31 & 9.29 \\
\hline Standard Deviation & 0.83 & 14.89 & 6.15 \\
\hline$\alpha$ & 0.96 & 0.93 & 0.93 \\
\hline
\end{tabular}

$* * p<.001$.

but not for participants in the low exposure severity region.

\section{Multivariate Analyses}

PTSD Symptoms. The results of the analysis concerning PTSD symptoms are presented in Table 3. These results revealed a linear effect of exposure severity $(\beta=.22, t=4.09$, $p<.001)$ but no quadratic effect $(\beta=-.01$, $t=-0.09, p=.93)$. This pattern shows that participants in high severity regions were at greater risk of reporting PTSD symptoms than those who lived in low severity regions. A main effect emerged for age $(\beta=-.28, t=$ $-4.40, p<.001)$ such that younger participants reported higher levels of PTSD than older participants. The main effect of narcissism also emerged $(\beta=.29, t=5.80, p<$ $.001)$, but this main effect was qualified by its interaction with the linear term for exposure severity $(\beta=.13, t=2.41, p=.02)$. The predicted values for this interaction are presented in Panel A of Figure 1. Simple slopes tests for the linear $\times$ narcissism interaction revealed that there was a significant linear association between exposure severity and PTSD symptoms for participants with high levels of narcissism $(\beta=.33, t=4.67, p<$ $.001)$ but not for participants with low levels of narcissism $(\beta=.09, t=1.18, p=.24)$. Further probing of these associations revealed that narcissism was associated with PTSD symptoms for those living in regions of Israel characterized by high exposure severity $(\beta=.38, t=5.17, p<.001)$ and moderate exposure severity $(\beta=.29, t=3.41, p=.001)$ but not for those living in areas with low exposure severity $(\beta=.03, t=0.20, p=.84)$. Taken together, these results show that there 
TABLE 3. Regression of PTSD Symptoms and GAD Symptoms on Age, Educational Level, Exposure Severity (Linear and Quadratic), and Pathological Narcissism

\begin{tabular}{|c|c|c|c|c|c|c|}
\hline & \multicolumn{3}{|c|}{ PTSD Symptoms } & \multicolumn{3}{|c|}{ GAD Symptoms } \\
\hline & $R^{2}$ & $\Delta R^{2}$ & $\beta$ & $R^{2}$ & $\Delta R^{2}$ & $\beta$ \\
\hline Step 1 & $.14 * * *$ & $.14 * * *$ & & $.14 * * *$ & $.14 * * *$ & \\
\hline Age & & & $-.28 * * *$ & & & $-.28 * * *$ \\
\hline Education & & & .00 & & & -.02 \\
\hline Exposure (Linear) & & & $.22^{* * *}$ & & & $.21^{* * *}$ \\
\hline Exposure (Quadratic) & & & -.01 & & & -.02 \\
\hline Step 2 & $.22 * * *$ & $.08^{* * *}$ & & $.18 * * *$ & $.04 * * *$ & \\
\hline Pathological Narcissism & & & $.29 * * *$ & & & $.21 * * *$ \\
\hline Step 3 & $.23 * * *$ & $.02 *$ & & $.19 * * *$ & $.01 *$ & \\
\hline Linear $\times$ Narcissism & & & $.13^{*}$ & & & $.14^{*}$ \\
\hline Quadratic $\times$ Narcissism & & & -.01 & & & -.07 \\
\hline
\end{tabular}

$* p<.05 . * * p<.001$.

is a linear association between exposure severity and self-reported PTSD symptoms for individuals with high levels of pathological narcissism but not for those with low levels of pathological narcissism.

GAD Symptoms. The results of the analysis concerning GAD symptoms are also presented in Table 3. Similar to the results for PTSD symptoms, the results for GAD symptoms revealed a linear effect of exposure severity $(\beta=.21, t=3.85, p<.001)$ but no quadratic effect $(\beta=-.02, t=-0.40, p=.69)$. This pattern shows that participants living in highly exposed regions that were at greater risk of experiencing missile strikes reported experiencing more GAD symptoms than those who lived in regions that were at lower risk. A main effect emerged for age $(\beta=-.28, t=$ $-4.37, p<.001)$, such that younger participants reported more GAD symptoms than older participants. The main effect of narcissism also emerged $(\beta=.21, t=4.09, p<$ .001 ), but this main effect was qualified by its interaction with the linear term for exposure severity ( $\beta=.14, t=2.44, p=.02)$. The predicted values for this interaction are presented in Panel B of Figure 1. Simple slopes tests for the linear $\times$ narcissism interaction revealed that there was a significant linear association between exposure severity and GAD symptoms for participants with high levels of narcissism $(\beta=.33, t=4.49, p<$ .001 ) but not participants with low levels of narcissism $(\beta=.07, t=0.95, p=.34)$. Further probing of these associations revealed that narcissism was associated with GAD symptoms for those with high exposure severity $(\beta=.27, t=3.55, p=.001)$ and moderate exposure severity $(\beta=.27, t=3.19, p$ $=.002$ ) but not for those with low exposure severity $(\beta=-.15, t=-1.20, p=.24)$. Taken together, these results show that there is a linear association between exposure severity and self-reported GAD symptoms for individuals with high levels of pathological narcissism but not for those with low levels of pathological narcissism.

\section{DISCUSSION}

This was the first study to assess Israeli civilians exposed to the November 14-21, 2012, eruption of violence in the Middle East between Israel and its neighbors in the Gaza Strip. The participants were female adults located in various areas in Israel where there 

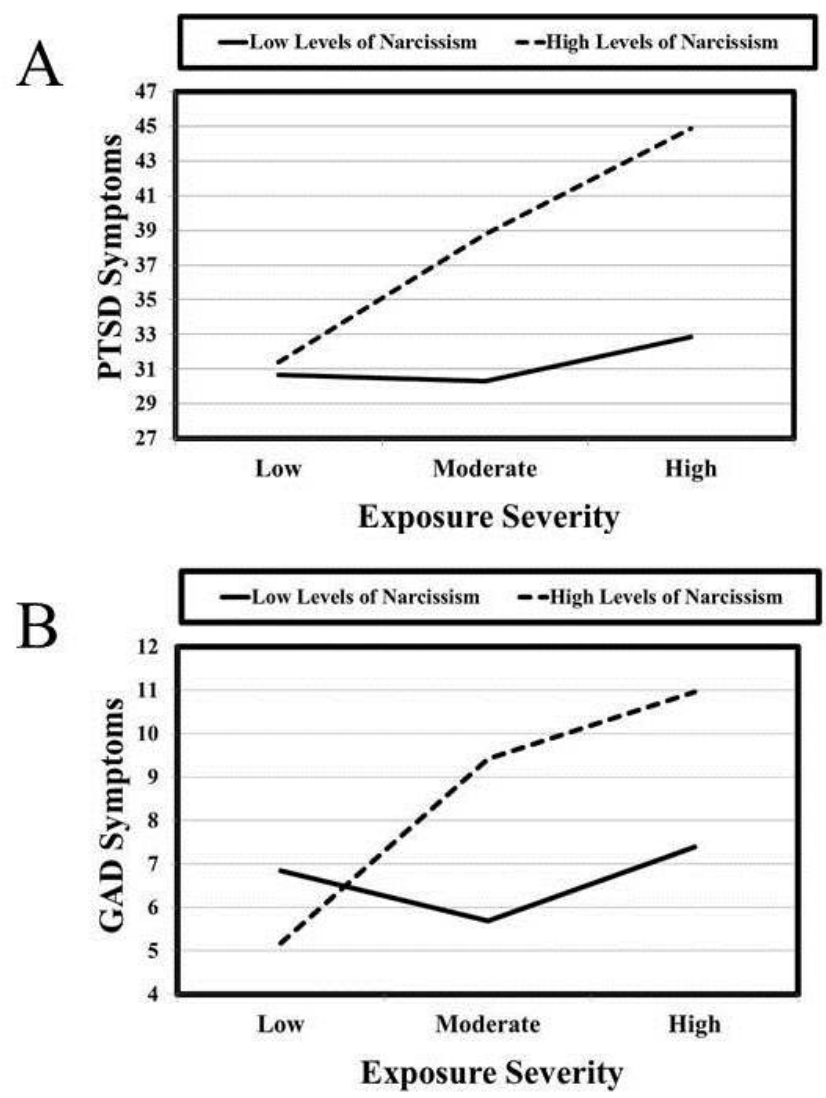

FIGURE 1. Predicted Values for PTSD Symptoms (Panel A) and GAD Symptoms (Panel B) That Illustrate the Interaction of Exposure Severity and Pathological Narcissism (at Values That Were One Standard Deviation Above and Below Its Mean).

was high, moderate, or low risk of incoming missile and rocket fire. Our results revealed a linear association between exposure severity and self-reported PTSD and GAD symptoms. However, this association was moderated by pathological narcissism such that exposure severity was associated with these psychological outcomes for participants with high levels of pathological narcissism but not for those with low levels of pathological narcissism. These results extend our understanding of the role that narcissistic personality features may play in the acute anxiety symptoms that individuals report in the aftermath of traumatic events (e.g., Bachar et al., 2005).
The findings highlight the role of personality features in the development of psychological symptoms following exposure to uncontrollable and potentially traumatic events. More specifically, it appears that pathological narcissism may serve as a diathesis that increases the likelihood that individuals develop psychopathological responses to trauma. These findings have clinical implications. It suggests that, as in other treatment domains such as general medical care (e.g., Magidson et al., 2012), it may be helpful to take pathological narcissism into account when determining the treatment needs of individuals following traumatic crises. For example, Simon (2002) suggested 
that patients with narcissistic personality features may require distinctive therapeutic interventions that recognize the activation of their narcissistic dynamics (e.g., omnipotent control, perfectionism, entitlement) and vulnerabilities (e.g., shame, rage, devaluation, interpersonal withdrawal, suicidality) following exposure to traumatic events (see also Kealy \& Rasmussen, 2012; Ogrodniczuk, 2013; Pincus, Cain, \& Wright, in press; Ronningstam, 2012). Future research should examine whether pathological narcissism moderates the efficacy of standard treatments for PTSD and GAD.

Pathological narcissism is associated with relatively poor interpersonal relationship functioning under normal conditions (Dickinson \& Pincus, 2003; Ogrodniczuk \& Kealy, 2013). The reason for this connection appears to be due to the fact that individuals high in narcissism are uncertain about their feelings of self-worth which may lead to either overt grandiosity or social withdrawal and avoidance (Pincus \& Lukowitsky, 2010). Neither of these responses is conducive to the formation of strong, healthy interpersonal relationships with others. This is important because previous research has shown a clear association between interpersonal relationships and psychological adjustment such that those individuals who experience greater social support demonstrate greater resilience in the wake of aversive experiences (e.g., Wilcox, 1981). It is possible that their impoverished interpersonal relationships may play at least some role in the heightened responses of individuals with narcissistic personality features to potentially life-threatening events. That is, individuals with narcissistic personality features may report more acute anxiety symptoms in the aftermath of potentially traumatic experiences in part because they do not have the advantage of utilizing supportive relationships with others to buffer the impact of these stressful experiences.

It is important to note that the bivariate associations pathological narcissism had with PTSD and GAD symptoms were not significant in the low severity exposure co- hort, but these associations were significant in the moderate and severe exposure cohorts. Examination of the standard deviations for symptom scores in Table 2 indicates they are comparable across exposure groups. Thus, the lack of associations in the low exposure group is not due to a restriction of range. This further supports the view of pathological narcissism as a diathesis for trauma-related symptoms and the clinical importance of future research concerning the psychological mechanisms employed by individuals with narcissistic personality features when coping with stress and trauma. As expected, higher levels of pathological narcissism were associated with greater dysregulation under conditions of threat, which is consistent with the views of narcissism outlined by Kernberg (1975) and Horowitz (1975). The manifestation of these symptoms of dysregulation would likely be of significant clinical interest so it may be informative for future research to examine whether pathological narcissism is more closely associated with the externalizing or internalizing features of PTSD in the immediate aftermath of exposure to traumatic events (Miller, Greif, \& Smith, 2003; Wolf, Miller, Harrington, \& Reardon, 2012). Pathological narcissism is also related to general externalizing (e.g., violence; Ellison et al., 2013) and internalizing (e.g., depression; Kealy, Tsai, \& Ogrodniczuk, 2012) symptoms in clinical outpatients. This suggests the possibility that future research may reveal that pathological narcissism is significantly associated with both internalizing and externalizing features of PTSD.

Despite the strengths of the present study (e.g., large sample of participants under acute threat), this research also has a number of limitations. First, due to the small number of men who completed the questionnaires, only women were included in the final set of analyses. The reason for this decision was that we had an inadequate number of male participants to allow us to determine whether the observed results emerged for both men and women with high levels of pathological narcissism. As a result, 
we decided to limit ourselves to an examination of our female participants. However, it may be helpful for future research to include both male and female participants because men and women have been found to respond differently to traumatic events (Kimerling, Ouimette \& Weitlauf, 2007: Neria, Nandi, \& Galea, 2008). For example, women have been found to develop PTSD at higher rates than men and PTSD tends to be more likely to develop into a chronic condition in women than men (see Tolin \& Foa, 2008, for a review). In addition to being exclusively female, our sample was also relatively young, which may limit the generalizability of these results. Second, a number of demographic differences were found between the regions (e.g., age and educational level). Due to the unique circumstances under which the study was conducted, we did not have an opportunity to make sure that the participants from the three regions were perfectly matched in terms of their demographic features. We attempted to control for these demographic differences by including them in our regression models. Third, we used a snowball sampling technique that increased the likelihood that individuals with more social connections-such as a larger number of friends and greater contact with family members-would receive some communication about the study. This may have led to an underrepresentation of those individuals who have fewer social connections in the present study. In the service of recruiting individuals under threat as quickly as possible, we believe the limitations associated with this sampling procedure were an acceptable trade-off, but future studies of this sort may benefit from using other strategies for recruiting participants (e.g., random sampling from the exposure severity regions). Fourth, our measures of PTSD symptoms and GAD symptoms were highly correlated regardless of the level of exposure severity. This suggests that these measures may have been tapping into a common "acute anxiety symptom" construct rather than capturing truly distinct symptom clusters. It may be helpful for future researchers to include other measures that capture a broader set of reactions to potentially traumatic events (e.g., depressive symptoms). Fifth, we did not include measures of other personality features in the present study. As a result, we were unable to determine whether the observed results were unique to pathological narcissism, although they were consistent with our theoretically derived hypotheses. Future researchers may want to assess a broader array of personality features so that they can address this issue. Lastly, our underlying process model was that pathological narcissism would serve as a vulnerability that would exacerbate the responses of individuals to potentially traumatic experiences. Although our results are consistent with this proposal, the actual causal sequencing of these events remains unclear due to the correlational nature of our data. For example, it is possible that the level of pathological narcissism reported by our participants may have been influenced by their level of exposure to the trauma. However, this possibility is unlikely given that there were no differences in the levels of pathological narcissism reported by individuals in the three exposure severity regions. It may be useful for future studies concerning the connection between narcissism and responses to potentially traumatic events to utilize longitudinal designs that follow individuals over extended periods of time to allow for a clearer understanding of the causal connection between pathological narcissism and responses to traumatic events.

Despite the limitations of the present study, we were able to investigate an important phenomenon and make significant contributions to our understanding of the connections between personality and the development of psychological symptoms in response to traumatic experiences. The study focused on participants who reported their experiences as they occurred (i.e., under "in vivo" life-threatening conditions) rather than relying on retrospective accounts of the events or utilizing laboratory simulations that lack the salience of real-world experi- 
ences. Moreover, to the best of our knowledge, the present study represents the first attempt to study pathological narcissism and its associations with acute anxiety symptoms (PTSD and GAD symptoms) among warzone civilians experiencing uncontrollable, life-threatening attacks. Notably, the findings of the present study suggest the possibility that pathological narcissism may render individuals more vulnerable to acute anxiety symptoms under conditions of immediate, severe threat. It is important to note that our findings indicate the need to take both environmental stressors and intrapersonal processes into account when considering how individuals respond to potentially traumatic events. The evidence that higher levels of pathological narcissism exacerbate the associations that exposure severity has with PTSD and GAD symptoms points to the possibility that narcissistic self- and affectiveregulation processes (e.g., Morf, Torchetti, \& Schürch, 2011) may include important, active intrapsychic components that give rise to unique person-environment interactions (e.g., Eaton, South, \& Krueger, 2009; Roche et al., in press).

\section{REFERENCES}

Abraham, K. (1921). Comments from the symposium on the war neuroses. In S. Ferenczi, K. Abraham, E. Simmel, \& E. Jones (Eds.), Psychoanalysis and the war neuroses (pp. 22-29). London: International Psycho-Analytical Press.

Ahern, J., Galea, S., Resnick, H., \& Vlahov, D. (2004). Television images and probable posttraumatic stress disorder after September 11: The role of background characteristics, event exposures, and perievent panic. Journal of Nervous and Mental Disease, 192, 217-226. doi:10.1097/01. nmd.0000144695.02982.41

Aiken, L. S., \& West, S. G. (1991). Multiple regression: Testing and interpreting interactions. Newbury Park, CA: Sage.

American Psychiatric Association. (1994). Diagnostic and statistical manual of mental disorders (4th ed.). Washington, DC: American Psychiatric Association.

Bachar, E., Hadar, H., \& Shalev, A. (2005). Narcissistic vulnerability and the development of PTSD: A prospective study. Journal of Nervous and Mental Disease, 193, 762-765. doi:10.1097/01. nmd.0000185874.31672.a5

Barry, C. T., Pickard, J. D., \& Ansel, L. L. (2009). The associations of adolescent invulnerability and narcissism with problem behaviors. Personality and Individual Differences, 47, 577-582. doi:10.1016/j.paid.2009.05.022

Besser, A., \& Neria, Y. (2009). PTSD symptoms, satisfaction with life, and prejudicial attitudes toward the adversary among Israelis exposed to ongoing terrorist attacks. Journal of Traumatic Stress, 22, 268-275. doi:10.1002/jts.20420

Besser, A., \& Neria, Y. (2010). The effects of insecure attachment orientations and perceived social support on posttraumatic stress and depressive symptoms among civilians exposed to the 2009 Israel-Gaza war: A follow-up cross-lagged panel design study Journal of Research in Personality, 44, 335-341. doi:10.1016/j.jrp.2010.03.004

Besser, A., \& Neria, Y. (2012). When home isn't a safe haven: Insecure attachment, perceived social support, and PTSD symptoms among Israeli evacuees from a battlefront still under threat. Psychological Trauma, 4, 34-46. doi:10.1037/a0017835

Besser, A., Neria, Y., \& Haynes, M. (2009). Adult attachment, perceived stress, and PTSD among civilians continuously exposed to terrorism in southern Israel. Personality and Individual Differences, 47, 851-857. doi:10.1016/j. paid.2009.07.003

Besser, A., \& Priel, B. (2010a). Personality vulnerability, low social support, and maladaptive cognitive emotion regulation under ongoing exposure to terrorist attacks. Journal of Social and Clinical Psychology, 29, 166-201. doi:10.1521/ jscp.2010.29.2.166

Besser, A., \& Priel, B. (2010b). Grandiose narcissism versus vulnerable narcissism in threatening situations: Emotional reactions to achievement failure and interpersonal rejection Journal 
of Social and Clinical Psychology, 29, 874-902. doi:10.1521/jscp.2010.29.8.874

Besser, A., \& Zeigler-Hill, V. (2010). The influence of pathological narcissism on emotional and motivational responses to negative events: The roles of visibility and concern about humiliation. Journal of Research in Personality, 44, 520-534. doi:10.1016/j.jrp.2010.06.006

Besser, A., \& Zeigler-Hill, V. (2011). Pathological forms of narcissism and perceived stress during the transition to the university: The mediating role of humor styles. International Journal of Stress Management, 18, 197-221. doi:10.1037/ a0024826

Clemence, A, J., Perry, J. C., \& Plakun, E. M. (2009). Narcissistic and borderline personality disorders in a sample of treatment refractory patients. Psychiatric Annuals, 39, 175-184.

Cox, B., MacPherson, P. S. R., Enns, M. W., \& McWilliams, L. A. (2004). Neuroticism and selfcriticism associated with posttraumatic stress disorder in a nationally representative sample. Behaviour Research and Therapy, 42, 105-114. doi:10.1016/S0005-7967(03)00105-0

Dickinson, K. A., \& Pincus, A. L. (2003). Interpersonal analysis of grandiose and vulnerable narcissism. Journal of Personality Disorders, 17, 188-207. doi:10.1521/pedi.17.3.188.22146

Eaton, N. R., South, S. C., \& Krueger, R .F. (2009). The Cognitive-Affective Processing System (CAPS) approach to personality and the concept of personality disorder: Integrating clini$\mathrm{cal}$ and social-cognitive research. Journal of $R e$ search in Personality, 43, 208-217. doi:10.1016/j. jrp.2009.01.016

Elliott, C. H., \& Lassen, M. K. (1997). A schema polarity model for case conceptualization, intervention and research. Clinical Psychology, 4, 1228. doi:10.1111/j.1468-2850.1997.tb00095.x

Ellison, W. D., Levy, K. N., Cain, N. M., Ansell, E. B., \& Pincus, A. L. (2013). The impact of pathological narcissism on psychotherapy utilization, initial symptom severity, and early-treatment symptom change: A naturalistic investigation. Journal of Personality Assessment, 95, 291-300. doi:10.1080/00223891.2012.742904

Fetterman, A.K., \& Robinson, M.D. (2010). Contingent self-importance among pathologi- cal narcissists: Evidence from an implicit task. Journal of Research in Personality, 44, 691-697. doi:10.1016/j.jrp.2010.09.002

Foa, E. B., \& Riggs, D. S. (1993). Post-traumatic stress disorder in rape victims. In J. Oldham, M. B. Riba, \& A. Tasman (Eds.), Review of psychiatry (vol. 12., pp. 273-303). Washington, DC: American Psychiatric Association.

Galea, S., Ahern, J., Resnick, H., Kilpatrick, D., Bucuvalas, M., Gold, J., et al. (2002). Psychological sequelae of the September 11 terrorist attacks in New York City. New England Journal of Medicine, 346, 982-987. doi:10.1056/NEJMsa013404

Garfield, D., \& Leveroni, C (2000). The use of self-psychological concepts in a Veterans Affairs PTSD clinic. Bulletin of the Menninger Clinic, 64, 344-364.

Ghafoori, B., Neria, Y., Olfson, M., Gameroff, M. J., Lantigua, R., Shea, S., et al. (2009). Screening of generalized anxiety disorder after terrorist attacks: A study in primary care. Journal of Traumatic Stress, 22, 218-226. doi:10.1002/jts.20419

Hobfoll, S. E., Canetti-Nisim, D., Johnson, R. J., Palmieri, P. A., Varley, J. D., \& Galea, S. (2008). The association of exposure, risk, and resiliency factors with PTSD among Jews and Arabs exposed to repeated acts of terrorism in Israel. Journal of Traumatic Stress, 21, 9-21. doi:10.1002/ jts.20307

Hopwood, C. J., Ansell, E. B., Pincus, A. L., Wright, A. G. C., Lukowitsky, M. R., \& Roche, M. J. (2011). The circumplex structure of interpersonal sensitivities. Journal of Personality, 79, 707740. doi:10.1111/j.1467-6494.2011.00696.x

Horowitz, M. J. (1975). Sliding meanings: A defense against threat in narcissistic personalities. International Journal of Psychoanalytic Psychotherapy, 4, 167-180.

Johnson, W. B. (1995). Narcissistic personality as a mediating variable in manifestations of posttraumatic stress disorder. Military Medicine, 160, 40-41.

Jordan, N. N., Hoge, C. W., Tobler, S. K., Wells, J., Dydek, G. J., \& Egerton, W. E. (2004). Mental health impact of the 9/11 Pentagon attack: Validation of a rapid assessment tool. American Journal of Preventive Medicine 26, 284-293. doi:10.1016/j.amepre.2004.01.005 
Kealy, D., \& Rasmussen, B. (2012). Veiled and vulnerable: The other side of grandiose narcissism. Clinical Social Work, 40, 356-366. doi:10.1007/ s10615-011-0370-1

Kealy, D., Tsai, M., \& Ogrodniczuk, J. S. (2012). Depressive tendencies and pathological narcissism among psychiatric outpatients. Psychiatry Research, 196, 157-159. doi:10.1016/j.psychres.2011.08.023

Kelman, H. (1946). The traumatic syndrome. American Journal of Psychoanalysis, 6, 12-19. doi:10.1007/BF01873949

Kernberg, O. F. (1975). Borderline conditions and pathological narcissism. New York: Aronson.

Kernberg, O. F. (1998). Pathological narcissism and narcissistic personality disorder: Theoretical background and diagnostic classification. In E. Ronningstam (Ed.), Disorders of narcissism: Diagnostic, clinical, and empirical implications (pp. 29-51). Washington DC: American Psychiatric Press.

Kimerling, R., Ouimette, P., \& Weitlauf, J. C. (2007). Gender issues in PTSD. New York: Guilford.

Liverant, G. I., Hoffman, S. G., \& Litz, B. T. (2004). Coping and anxiety in college students after the September 11th terrorist attacks. Anxiety, Stress, and Coping, 17, 127-139. doi:10.1080/0003379042000221412

Magidson, J. F., Collado-Rodriguez, A., Madan, A., Perez-Camoirano, N. A., Galloway, S. K., Brockardt, J. J., ... \& Miller, J. D. (2012). Addressing narcissistic personality features in the context of medical care: Integrating diverse perspectives to inform clinical practice. Personality Disorders: Theory, Research, and Treatment, 3, 196-208. doi:10.1037/a0025854

McCullough, M. E., Emmons, R. A., Kilpatrick, S. D., \& Mooney, C. N. (2003). Narcissists as "victims": The role of narcissism in the perception of transgressions. Personality and Social Psychology Bulletin, 29, 885-893. doi:10.1177/0146167203029007007

Miller, M. W., Greif, J. L., \& Smith, A. A. (2003). Multidimensional Personality Questionnaire profiles of veterans with traumatic combat exposure: Externalizing and internalizing sub- types. Psychological Assessment, 15, 205-215. doi:10.1037/1040-3590.15.2.205

Morf, C., \& Rhodewalt, F. (2001). Unraveling the paradoxes of narcissism: A dynamic self-regulatory processing model. Psychological Inquiry, 12, 177-196. doi:10.1207/S15327965PLI1204_1

Morf, C. C., Torchetti, T., \& Schürch, E. (2011). Narcissism from the perspective of the dynamic self-regulatory processing model. In W. K. Campbell \& J. D. Miller (Eds.), The handbook of narcissism and narcissistic personality disorder: Theoretical approaches, empirical findings, and treatment (pp. 56-70). Hoboken, NJ: Wiley.

Neria, Y., Besser, A., Kipper, D., \& Westphal, M. (2010). A longitudinal study of posttraumatic stress disorder, depression, and generalized anxiety disorder in civilians exposed to war trauma. Journal of Traumatic Stress, 23, 322-330. doi:10.1002/jts.20522

Neria, Y., Gross, R., Olfson, M., Gameroff, M., Wickramaratne, P., Das, A., Weissman, M. M. (2006). Posttraumatic stress disorder in primary care one year after the 9/11 attacks. General Hospital Psychiatry, 28, 213-222. doi:10.1016/j.genhosppsych.2006.02.002

Neria, Y., Nandi, A., \& Galea, S. (2008). Posttraumatic stress disorder following disasters: A systematic review. Psychological Medicine, 38, 467-480. doi:10.1017/S0033291707001353

Norris, F., Friedman, M., Watson, P., Byrne, C., Diaz, E., \& Daniasty, K. (2002). 60,000 disaster victims speak: I. An empirical review of the empirical literature, 1981-2001. Psychiatry, 65, 207-239. doi:10.1521/psyc.65.3.240.20169

Ogrodniczuk, J. S. (2013). Understanding and treating pathological narcissism. Washington, DC: American Psychological Association.

Ogrodniczuk, J. S., \& Kealy, D. (2013). Interpersonal problems of narcissistic patients. In J. S. Ogrodniczuk (Ed.), Understanding and treating pathological narcissism (pp. 113-127). Washington, DC: American Psychological Association.

Pincus, A. L. (2013). The Pathological Narcissism Inventory. In J. S. Ogrodniczuk (Ed.), Understanding and treating pathological narcissism (pp. 93-110). Washington, DC: American Psychological Association. 
Pincus, A. L., Ansell, E. B., Pimentel, C. A., Cain, N. M., Wright, A. G. C., \& Levy, K. N. (2009). Initial construction and validation of the Pathological Narcissism Inventory. Psychological Assessment, 21, 365-379. doi:10.1037/a0016530

Pincus, A. L., Cain, N.M., \& Wright, A. G. C. (in press). Narcissistic grandiosity and narcissistic vulnerability in psychotherapy. Personality Disorders: Theory, Research, and Treatment.

Pincus, A. L., \& Lukowitsky, M. R. (2010). pathological narcissism and narcissistic personality disorder. Annual Review of Clinical Psychology, 6, 421-446. doi:10.1146/annurev. clinpsy.121208.131215

Pincus, A. L., \& Roche, M. J. (2011). Narcissistic grandiosity and narcissistic vulnerability. In W. K. Campbell \& J. D. Miller (Eds.), Handbook of narcissism and narcissistic personality disorder: Theoretical approaches, empirical findings, and treatment (pp. 31-40). Hoboken, NJ: Wiley. doi:10.1037/a0021191

Pincus, A. L., Roche, M. J., \& Good, E. W. (in press). Narcissistic personality disorder and pathological narcissism. In P. H. Blaney, R. F. Krueger, \& T. Millon (Eds.), Oxford textbook of psychopathology (3rd ed., pp.). New York: Oxford University Press.

Reich, A. (1960). Pathologic forms of self-esteem regulation. Psychoanalytic Study of the Child, 15, 215-232.

Roche, M. J., Pincus, A. L., Conroy, D. E., Hyde, A., \& Ram, N. (in press). Pathological narcissism and interpersonal behavior in daily life. Personality Disorders: Theory, Research, and Treatment. doi:10.1037/a0030798

Ronningstam, E. (2011). Psychoanalytic theories on narcissism and narcissistic personality. In W. K. Campbell \& J. D. Miller (Eds.), Handbook of narcissism and narcissistic personality disorder: Theoretical approaches, empirical findings, and treatment (pp. 41-55). Hoboken, NJ: Wiley.

Ronningstam, E. (2012). Alliance building and narcissistic personality disorder. Journal of Clinical Psychology, 68, 943-953. doi:10.1002/ jclp. 21898

Shalev, A. Y., \& Freedman, S. (2005). PTSD following terrorist attacks: A prospective evaluation.
American Journal of Psychiatry, 162, 1188-1191. doi:10.1176/appi.ajp.162.6.1188

Simon, R. I. (2002). Distinguishing trauma-associated narcissistic symptoms from posttraumatic stress disorder: A diagnostic challenge. Harvard Review of Psychiatry 10, 28-36. doi:10.1093/ $\mathrm{hrp} / 10.1 .28$

Spitzer, R. L., Kroenke, K., Williams, J. B., \& Lowe, B. A. (2006). Brief measure for assessing generalized anxiety disorder: The GAD-7. Archives of Internal Medicine, 166, 1092-1097. doi:10.1001/archinte.166.10.1092

Stinson, F. S., Dawson, D. A., Goldstein, R. B., Chou, S.P., Huang, B., Smith, S. M., Ruan, W. J., Pulay, A. J., Saha, T. D., Pickering, R. P., \& Grant, B. F. (2008). Prevalence, correlates, disability, and comorbidity of DSM-IV narcissistic personality disorder: Results from the wave 2 national epidemiologic survey on alcohol and related conditions. Journal of Clinical Psychiatry 69, 10331045. doi:10.4088/JCP.v69n0701

Thomas, K. M., Wright, A. G. C., Lukowitsky, M. R., Donnellan, M. B., \& Hopwood, C. J. (2012). Evidence for the criterion validity and clinical utility of the pathological narcissism inventory. Assessment, 19, 135-145. doi:10.1177/1073191112436664

Tolin D. F., \& Foa, E. B. (2008). Sex differences in trauma and posttraumatic stress disorder: A quantitative review of 25 years of research. Psychological Trauma, S(1), 37-85. doi:10.1037/19429681.S.1.37

Ulman, R. G., \& Brothers, D. (1987). A self-psychological reevaluation of posttraumatic stress disorder (PTSD) and its treatment: Shattered fantasies. Journal of the American Academy of Psychoanalysis, 15, 175-203.

Weathers, F. W., \& Ford, J. (1996). Psychometric properties of the PTSD checklist (PCL-C, PCL-S, PCL-M, PCL-PR). In B. H. Stamm (Ed.), Measurement of stress, trauma, and adaptation (pp. 250-252). Lutherville, MD: Sidran Press.

Weinberg, M., Besser, A., Campeas, M., Shvil, E., \& Neria, Y. (2012). Civilians exposed to terrorism and war trauma in Israel: The role of intraand inter-personal factors. In A. M. Columbus (Ed.), Advances in Psychology Research (vol. 94, pp. 1-53). Hauppauge, NY: Nova. 
Wilcox, B. L. (1981). Social support, life stress, and psychological adjustment: A test of the buffering hypothesis. American Journal of Community Psychology, 9, 371-386.

Wolf, E. J., Miller, M. W., Harrington, K. M., \& Reardon, A. (2012). Personality-based latent classes of posttraumatic psychopathology: Personality disorders and the internalizing/externalizing model. Journal of Abnormal Psychology, 121, 256-262. doi:10.1037/a0023237

Zeigler-Hill, V., \& Besser, A. (2013). A glimpse behind the mask: Facets of narcissism and feelings of self-worth. Journal of Personality Assessment,
95, 249-260. doi:10.1080/00223891.2012.7171 50

Zeigler-Hill, V., \& Jordan, C. H. (2011). Behind the mask: Narcissism and implicit self-esteem. In W. K. Campbell \& J. Miller (Eds.), Handbook of narcissism and narcissistic personality disorder: Theoretical approaches, empirical findings, and treatment (pp. 101-115). Hoboken, NJ: Wiley.

Zeigler-Hill, V., Myers, E. M., \& Clark, C. B. (2010). Narcissism and self-esteem reactivity: The role of negative achievement events. Journal of Research in Personality, 44, 285-292. doi:10.1016/j. jrp.2010.02.005 
Copyright of Psychiatry: Interpersonal \& Biological Processes is the property of Guilford Publications Inc. and its content may not be copied or emailed to multiple sites or posted to a listserv without the copyright holder's express written permission. However, users may print, download, or email articles for individual use. 